\title{
Metal-Containing Ionic Liquids: Highly Effective Catalysts for Degradation of Poly(Ethylene Terephthalate)
}

\author{
Qun Feng Yue, ${ }^{1,2,3}$ Hua Guang Yang, ${ }^{1}$ Mi Lin Zhang, ${ }^{3}$ and Xue Feng Bai ${ }^{2,3}$ \\ ${ }^{1}$ College of Chemistry and Chemical Engineering, Harbin Normal University, Harbin 150025, China \\ ${ }^{2}$ Key Laboratory of Chemical Engineering Process \& Technology for High-Efficiency Conversion, \\ College of Heilongjiang Province, School of Chemistry and Material Sciences, Heilongjiang University, \\ Harbin 150080, China \\ ${ }^{3}$ Institute of Petrochemistry, Heilongjiang Academy of Sciences, Harbin 150040, China \\ Correspondence should be addressed to Qun Feng Yue; qunfengyue@gmail.com
}

Received 6 November 2013; Revised 24 December 2013; Accepted 14 March 2014; Published 7 April 2014

Academic Editor: Markku Leskela

Copyright (C) 2014 Qun Feng Yue et al. This is an open access article distributed under the Creative Commons Attribution License, which permits unrestricted use, distribution, and reproduction in any medium, provided the original work is properly cited.

Poly(ethylene terephthalate) (PET) waste from local market was depolymerized by ethylene glycol (EG) in the presence of metalcontaining ionic liquids, and the qualitative analysis showed that the bis(hydroxyethyl) terephthalate (BHET) was the main product in this process. Compared with other metal-containing ionic liquids, $[\mathrm{Bmim}] \mathrm{ZnCl}_{3}$ was considered the best catalyst in the glycolysis of PET. When the reaction temperature was $180^{\circ} \mathrm{C}$, the conversion of PET reached $97.9 \%$ and the BHET was yielded to $83.3 \%$ within $5 \mathrm{~h}$. At the same time, $[\mathrm{Bmim}] \mathrm{ZnCl}_{3}$ could be reused for six times without obvious decrease in the yield of BHET. Additional, the effects of waste PET's source and size were investigated.

\section{Introduction}

Poly(ethylene terephthalate) (PET), a high volume thermoplastic polyester, is extensively used in diverse application textiles, high strength fibers, photographic films, soft-drink bottles, and others $[1,2]$. However, PET is also one of the largest components of the postconsumer plastics waste in landfills. Therefore, in the past few years, the interest in recycling PET was continuously growing because of ecological and economic considerations [3-5]. It is well known that three methods, hydrolysis, glycolysis, and aminolysis, have been developed for the chemical recycling of PET $[1,6-9]$. Since the bis-2-hydroxyethyl terephthalate (BHET) monomer can be produced by the glycolysis of PET waste in ethylene glycol (EG) and it has been widely used in the production of unsaturated polyesters, rigid or flexible polyurethanes, and other fine chemicals, the glycolysis of PET has attracted much attention recently $[1,10,11]$. But the glycolysis of PET is very sluggish in the absence of catalysts; various kinds of catalysts have been explored for this reaction, such as metal acetate, metal chloride, metal oxides, solid superacids, and titanium-phosphate [12-16]. These traditional catalysts are efficient, but they are noxious to environment and difficult to separate from the reaction mixture which would influence the property of the products.

Recently, ionic liquids (ILs) have been noticed by many researchers because of ILs' unique feature, such as a strong solvent power for organic and inorganic compounds, thermal stability, nonvolatility, electrochemical stability, and low flammability [17]. In 2009, Liu et al. [18] reported that the hydrolysis of PET was carried out with using [Bmim] Cl as a solvent and $\left[\mathrm{HSO}_{3} \mathrm{Pmim}\right] \mathrm{HSO}_{4}$ as a catalyst. In the same year, Wang et al. [19] reported the solubility of PET in different ionic liquids, such as $[\mathrm{Bmim}] \mathrm{Cl},[\mathrm{Bmim}] \mathrm{Br}$, $[$ Emim $] \mathrm{Br}, \quad[\mathrm{Bmim}] \mathrm{BF}_{4},[\mathrm{Bmim}] \mathrm{PF}_{4},[\mathrm{Bmim}] \mathrm{CH}_{3} \mathrm{COO}$, $[\mathrm{Bmim}] \mathrm{CF}_{3} \mathrm{COO}$, and $[\mathrm{Bmim}] \mathrm{AlCl}_{4}$. Their research showed that PET dissolved readily in $[\mathrm{Bmim}] \mathrm{AlCl}_{4}$, and the solubility of PET in ionic liquids, which contained $\mathrm{Cl}^{-}$, $\mathrm{Br}^{-}, \mathrm{CH}_{3} \mathrm{COO}^{-}$, and $\mathrm{CF}_{3} \mathrm{COO}^{-}$as a anion, was also good. More recently, Wang and coworkers also found [20] that the glycolysis of PET in EG was catalyzed by ionic liquids, and the conversion of PET reached $100 \%$ when $\left[3 \mathrm{a}-\mathrm{C}_{3} \mathrm{P}\left(\mathrm{C}_{4}\right)_{3}\right]$ [Gly] 


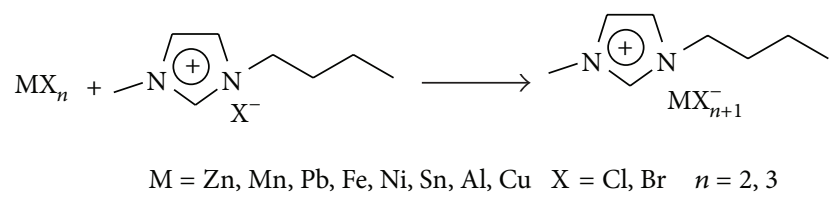

SCHeme 1: Synthesis of metal-containing ionic liquids.

and $\left[3 \mathrm{a}-\mathrm{C}_{3} \mathrm{P}\left(\mathrm{C}_{4}\right)_{3}\right][\mathrm{Ala}]$ were used as catalysts. But this kind of ionic liquids was very expensive. In the presence of $[\mathrm{Bmim}] \mathrm{Cl}$ and $[\mathrm{Bmim}] \mathrm{Br}$, the conversion of PET is $44.7 \%$ and $98.7 \%$, respectively, but the dosage of catalyst was very high $(20 \mathrm{wt} \%)$. Therefore, it is necessary to explore a new ionic liquid catalyst with high catalytic activity for the glycolysis of PET under mild reaction conditions.

In the present work, we prepared and characterized the metal-containing ionic liquids. Its catalytic activity was evaluated in the glycolysis of PET. A systematic investigation was conducted on the effects of reaction parameters and different PET products on the conversion of PET and the yield of BHET.

\section{Experimental}

2.1. Materials. PET flakes were prepared from drinking water bottle which was made by PepsiCo, Nongfu Spring Group Co. Ltd., nine-three oil Group Co. Ltd., and Tingyi (Cayman Islands) Holding Corporation Tingyi. The bottles' labels were removed and the bottles were cut into $1 \mathrm{~mm}^{2}$ flakes and subsequently dried. All other analytical reagents were purchased from chemical reagent companies and were used without further purification.

\subsection{Prepared Catalysts}

2.2.1. Synthesis of 1-Methyl-3-butylimidazolium Chloride $([\mathrm{Bmim}] \mathrm{Cl})$. The ionic liquid, 1-methyl-3-butylimidazolium chloride $([\mathrm{Bmim}] \mathrm{Cl})$, was synthesized according to the previous literature [21].

$[\mathrm{Bmim}] \mathrm{Cl}$ was synthesized by refluxing the 1methylimidazole with a large excess of the chlorobutane for $24 \mathrm{~h}$. The excess chlorobutane was removed by evaporation and crude product was recrystallized from acetonitrile/ethyl acetate. The resulting white precipitate was isolated by filtration and then dried in vacuo for $24 \mathrm{~h}$.

2.2.2. Synthesis of Metal-Containing Ionic Liquids. Equimolar amounts of $[\mathrm{Bmim}] \mathrm{Cl}$ and metal chloride $\left(\mathrm{ZnCl}_{2}, \mathrm{MnCl}_{2}\right.$, $\mathrm{PbCl}_{2}, \mathrm{FeCl}_{2}, \mathrm{NiCl}_{2}, \mathrm{AlCl}_{3}$, and $\mathrm{CuCl}_{2}$ ) were mixed for $8-24 \mathrm{~h}$ at room temperature in dichloromethane. Then, the dichloromethane was evaporated. Then, these metalcontaining ionic liquids were dried in a vacuum oven at $70^{\circ} \mathrm{C}$ for $24 \mathrm{~h}$ and the metal-containing ionic liquids were obtained (Scheme 1).

2.2.3. Glycolysis of PET. The PET waste was treated with ethylene glycol under reflux in the presence of different catalysts

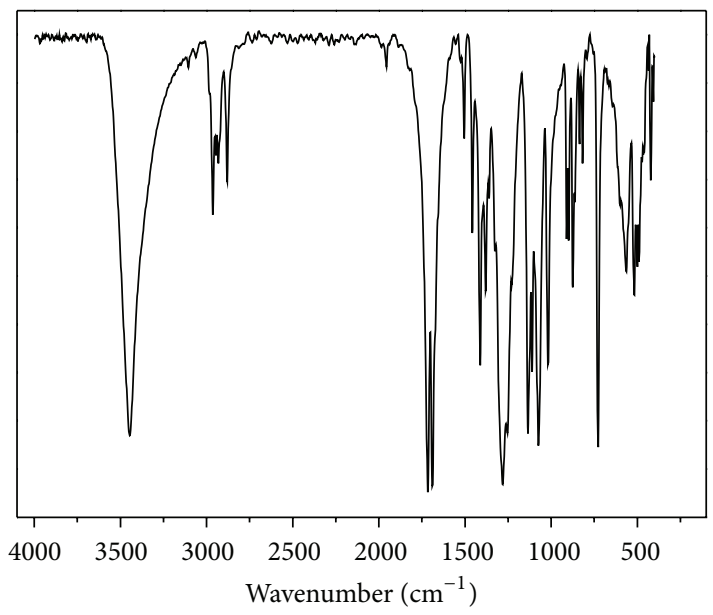

FIGURE 1: FT-IR spectra of main product of depolymerization.

for $5 \mathrm{~h}$. At the end of the reaction, distilled water was added in excess to the reaction mixture with vigorous agitation. The glycolyzed product was obtained as a residue after filtration. The filtrate contained unreacted EG, BHET, and soluble oligomer. White crystals of BHET were obtained by first concentrating the filtrate and then chilling it. The glycolyzed residue was then boiled with water to extract any BHET left. White crystalline powder of BHET was purified by recrystallization from water and dried in an oven at $90^{\circ} \mathrm{C}$ and then weighed for determining the yield of BHET. The main products of depolymerization were characterized by FT-IR, ${ }^{1} \mathrm{H}$ NMR, and Differential Scanning Calorimetry (DSC).

\section{Results and Discussions}

3.1. Analysis of Main Depolymerized Product. Purified main product was characterized by FT-IR, ${ }^{1} \mathrm{H}$ NMR, and DSC. From Figure 1, it can be clearly seen that the FT-IR spectrograph contained a $-\mathrm{OH}$ band at $3347 \mathrm{~cm}^{-1}$ and $1135 \mathrm{~cm}^{-1}$, a $\mathrm{C}=\mathrm{O}$ stretching at $1716 \mathrm{~cm}^{-1}$, an alkyl C-H at $2873 \mathrm{~cm}^{-1}$ and $2954 \mathrm{~cm}^{-1}$, and an aromatic $\mathrm{C}-\mathrm{H}$ at $1456-1504 \mathrm{~cm}^{-1}$. These results indicated that the product was BHET [22]. The proton NMR spectrum of the product was shown in Figure 2; the peak at $\delta 8.12 \mathrm{ppm}$ was assigned the four aromatic protons of BHET and the signals at $\delta 4.32 \mathrm{ppm}$ and $3.72 \mathrm{ppm}$ were characterized by the methylene protons of $\mathrm{COO}-\mathrm{CH}_{2}$ and $\mathrm{CH}_{2}-\mathrm{OH}$ in BHET. And the triplet at $\delta 4.92 \mathrm{ppm}$ was ascribed to the protons of hydroxyl in the BHET. The results of NMR spectrum were also accord very well to the ${ }^{1} \mathrm{H}$ NMR spectrum of BHET in the literature [23]. The DSC of depolymerization showed (Figure 3 ) reasonably sharp single endothermic peak at $112^{\circ} \mathrm{C}$, which agreed well with the known melting point of $\mathrm{BHET}$ which was reported in the literature [24]. The results of FT-IR, ${ }^{1} \mathrm{H}$ NMR, and DSC indicated that the main product was BHET.

3.2. Depolymerization of PET in the Presence of Catalysts. In the presence of $1 \mathrm{wt} \%$ metal-containing ionic liquids, the 


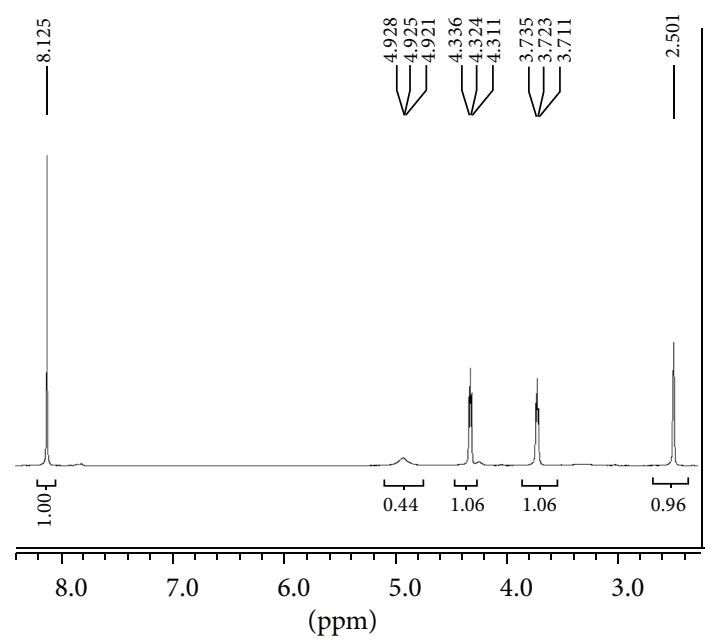

FIGURE 2: ${ }^{1} \mathrm{H}$ NMR spectra of main product of depolymerization.

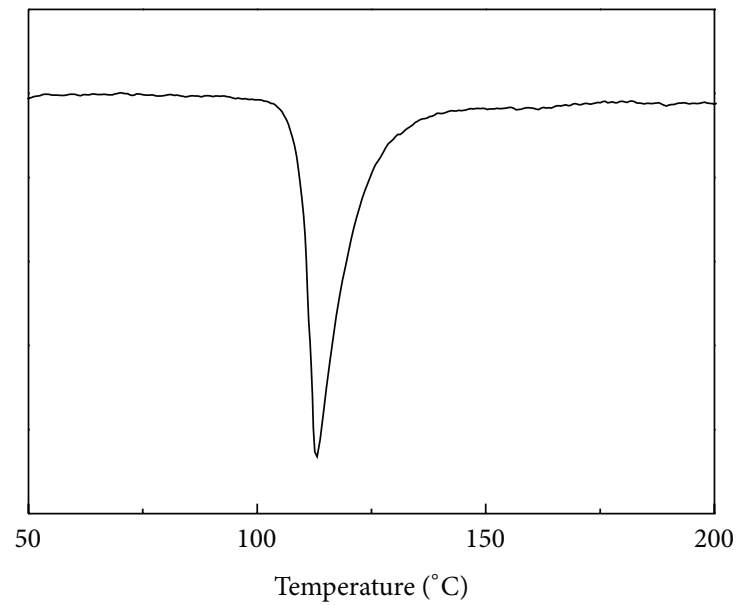

FIGURE 3: DSC curve of main product of depolymerization.

glycolysis of PET was carried out in ethylene glycol, and the results were shown in Figure 4. From Figure 4, it can be seen that the conversion of PET was $5.9 \%$ in the absence of a catalyst, but no BHET was detected. When the $[\mathrm{Bmim}] \mathrm{CuCl}_{3}$ was used as a catalyst, the conversion of PET was increased to $12.1 \%$, but the products were the oligomer and the trace of BHET. Similar results were obtained when the $[\mathrm{Bmim}] \mathrm{AlCl}_{4}$ and $[\mathrm{Bmim}] \mathrm{SnCl}_{3}$ were used as catalysts. When the metal ion was changed to Ni or Fe in the metal-containing ionic liquids, the conversion of PET was increased, yet the yield of BHET was very low. It was surprising that the $33.6 \%$ conversion of PET was given and the yield of BHET was increased to $20.7 \%$ when the metal-containing ionic liquid $[\mathrm{Bmim}] \mathrm{PbCl}_{3}$ was used as the catalyst. When the $\mathrm{Pb}^{2+}$ was changed to $\mathrm{Mn}^{2+}$ or $\mathrm{Zn}^{2+}$, the excellent conversion of PET and yield of BHET were obtained. In the presence of $\left[\mathrm{Bmim}_{\mathrm{ZnCl}}\right.$, the $97.9 \%$ conversion of PET was given, and the BHET was yielded to $83.3 \%$. It was probably due to the Lewis acid of ionic liquid

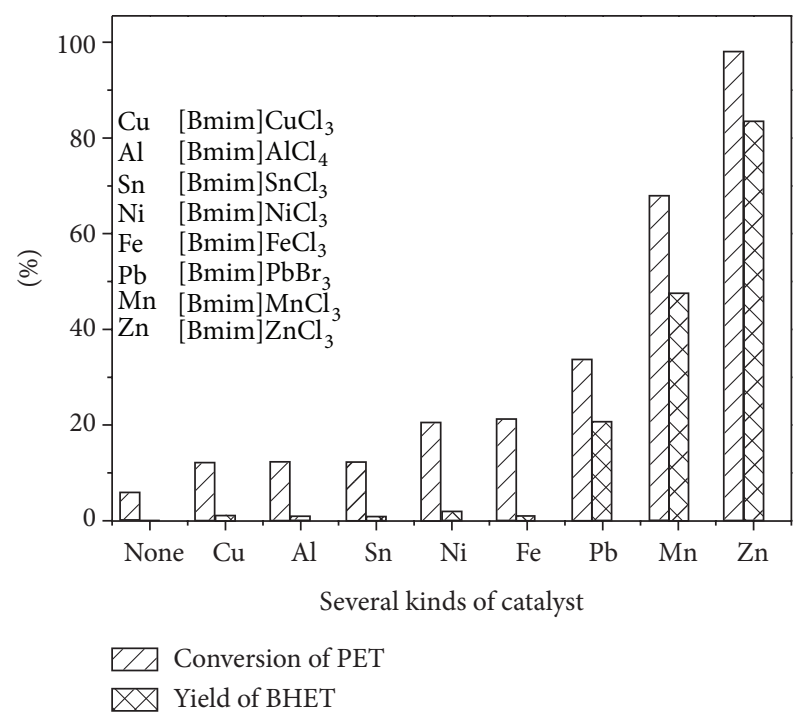

FIGURE 4: The effect of different catalysts on the glycolysis of PET. Reaction conditions: PET 2 g, catalyst $1 \mathrm{wt} \%$, reaction time $5 \mathrm{~h}$, and temperature $180^{\circ} \mathrm{C}$.

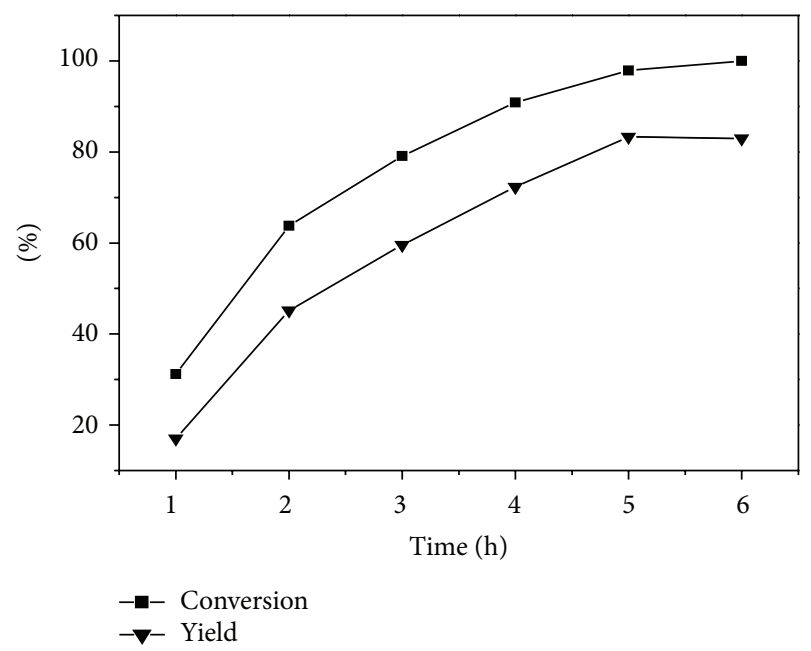

FIgURE 5: Effect of reaction time on the glycolysis of PET. Reaction conditions: PET $2 \mathrm{~g}$, $[\mathrm{Bmim}] \mathrm{ZnCl}_{3} 1 \mathrm{wt} \%$, and temperature $180^{\circ} \mathrm{C}$.

$[\mathrm{Bmim}] \mathrm{ZnCl}_{3}$. Form the results of glycolysis, $[\mathrm{Bmim}] \mathrm{ZnCl}_{3}$ was considered as the suitable catalyst.

\subsection{Optimized Reaction Conditions of Glycolysis in the Pres- ence of Zinc-Containing Ionic Liquid}

3.3.1. Effect of Reaction Time on the Glycolysis of PET. In the presence of $[\mathrm{Bmim}] \mathrm{ZnCl}_{3}$, the effects of reaction time were investigated (Figure 5). From Figure 5, it can be seen that the conversion of PET was increased when the reaction time was prolonged. When the reaction time was $6 \mathrm{~h}$, the conversion of PET was achieved $100 \%$. The yield of BHET was increased with prolonging reaction time from $1 \mathrm{~h}$ to $5 \mathrm{~h}$, and then the yield of BHET was decreased slightly when the reaction was 
TABLE 1: The catalytic effect of $[\mathrm{Bmim}] \mathrm{ZnCl}_{3}$ under different temperatures ${ }^{\mathrm{a}}$.

\begin{tabular}{lccc}
\hline Entry & Temperature $\left({ }^{\circ} \mathrm{C}\right)$ & Conversion $(\%)$ & Yield $(\%)$ \\
\hline 1 & 180 & 97.9 & 83.3 \\
2 & 175 & 75.5 & 58.9 \\
3 & 170 & 50.6 & 39.4 \\
4 & 165 & 30.6 & 23.1 \\
5 & 160 & 21.5 & 14.5 \\
\hline
\end{tabular}

${ }^{\mathrm{a}}$ Reaction conditions: PET $2 \mathrm{~g}$; $[\mathrm{Bmim}] \mathrm{ZnCl}_{3} 1 \mathrm{wt} \%$; reaction time $5 \mathrm{~h}$.

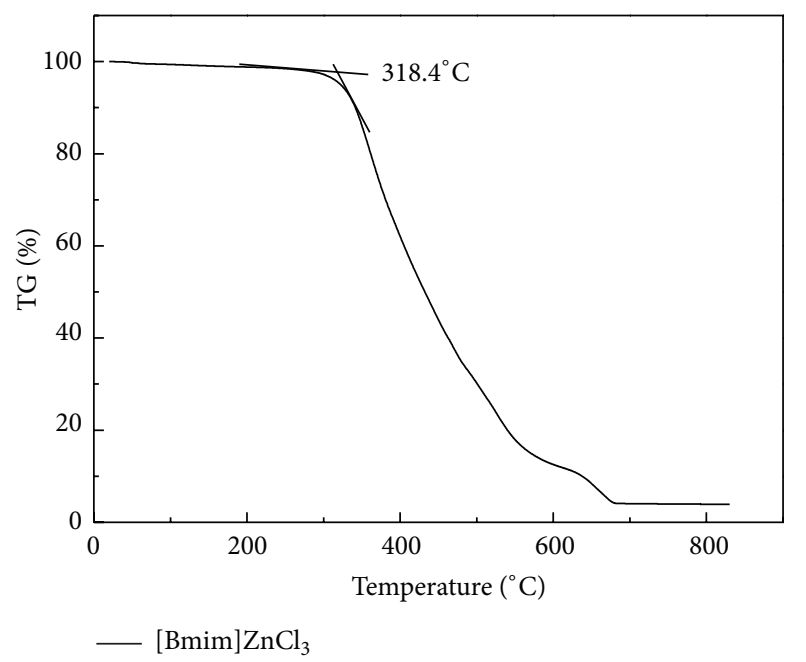

FIgURE 6: TG curve of $[\mathrm{Bmim}] \mathrm{ZnCl}_{3}$.

prolonged to $6 \mathrm{~h}$ from $5 \mathrm{~h}$. The results indicated that the yield of BHET was yielded to maxima when the reaction time was $5 \mathrm{~h}$.

3.3.2. Effect of Reaction Temperature on the Glycolysis of PET. The glycolysis reaction was carried in different temperatures and the results have been shown in Table 1 .

From Table 1, it can be seen that the conversion of PET and the yield of BHET were increased with increasing the reaction temperature. When the reaction was performed at $160^{\circ} \mathrm{C}$, the conversion of PET was $21.5 \%$ and the BHET was yielded to $14.5 \%$ (Table 1 , entry 5 ). With increasing the temperature to $180^{\circ} \mathrm{C}$, the conversion of PET was achieved $97.9 \%$, and the $83.3 \%$ BHET was given (Table 1, entry 1 ). To our best knowledge, this result was the best in the glycolysis of PET in EG.

3.3.3. Reusing Ability of Zinc-Containing Ionic Liquid. In the literature [25], $\mathrm{ZnCl}_{2}$ was found to be a good catalyst for the glycolysis of PET, but $\mathrm{ZnCl}_{2}$ could not be reused because it was sensitive to water. When zinc-containing ionic liquid was prepared from $[\mathrm{Bmim}] \mathrm{Cl}$ and $\mathrm{ZnCl}_{2}$, it was stable in water and could be reused [26]. At the same time, the thermal stability $[\mathrm{Bmim}] \mathrm{ZnCl}_{3}$ was determined (Figure 6). Figure 6 showed the TG curve of ionic liquid catalyst $[\mathrm{Bmim}] \mathrm{ZnCl}_{3}$ and it can be seen that the initiative

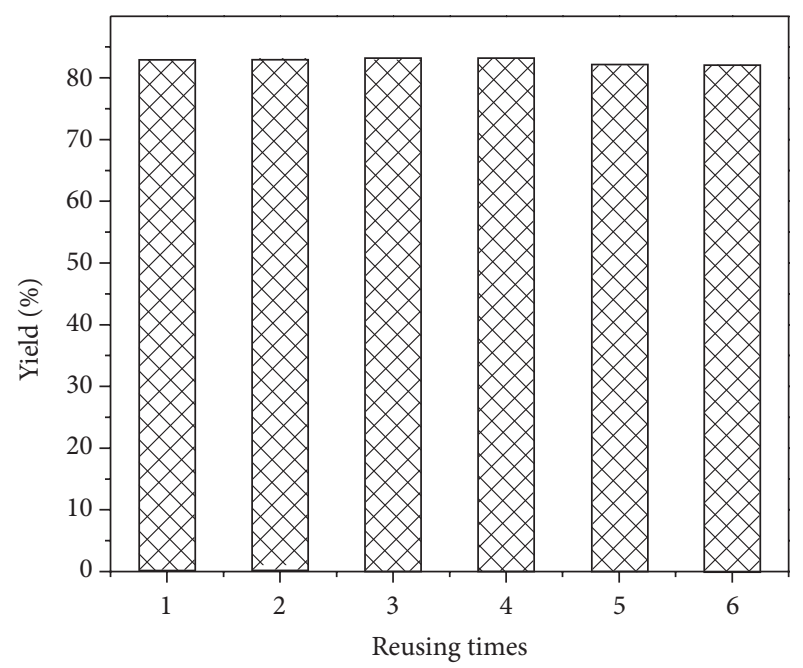

FIgURE 7: Reusability of $[\mathrm{Bmim}] \mathrm{ZnCl}_{3}$ in the glycolysis of PET. Reaction conditions: PET $2 \mathrm{~g},[\mathrm{Bmim}] \mathrm{ZnCl}_{3} 1 \mathrm{wt} \%$, reaction time $5 \mathrm{~h}$, and temperature $180^{\circ} \mathrm{C}$.

TABLE 2: Glycolysis of different PET products catalyzed by $[\mathrm{Bmim}] \mathrm{ZnCl}_{3}{ }^{\mathrm{a}}$.

\begin{tabular}{lcc}
\hline Product of PET & Conversion/\% & Yield/\% \\
\hline Mineral water & 100 & 78.6 \\
Pepsi Cola & 100 & 77.8 \\
Masterkong & 100 & 80.1 \\
Edible oil & 97.9 & 66.8 \\
Nongfu Spring pure water & 99.0 & 83.3 \\
\hline
\end{tabular}

${ }^{\mathrm{a}}$ Reaction conditions: PET $2 \mathrm{~g}$; $[\mathrm{Bmim}] \mathrm{ZnCl}_{3} 1 \mathrm{wt} \%$; reaction time $5 \mathrm{~h}$; reaction temperature $180^{\circ} \mathrm{C}$.

decomposition temperature of $[\mathrm{Bmim}] \mathrm{ZnCl}_{3}$ was $318.4^{\circ} \mathrm{C}$. It could be inferred that $[\mathrm{Bmim}] \mathrm{ZnCl}_{3}$ showed a good thermal stability in this process.

In order to investigate the stability of $[\mathrm{Bmim}] \mathrm{ZnCl}_{3}$, the reusability of $[\mathrm{Bmim}] \mathrm{ZnCl}_{3}$ was examined in the glycolysis. After the glycolysis, the oligomer, and monomer were separated from the reaction mixture, and $\left[\mathrm{Bmim}^{2} \mathrm{ZnCl}_{3}\right.$ was obtained by distillation and directly reused for subsequent reaction and the results were shown in Figure 7. It was shown that the catalyst could be reused for six times without obvious decrease in the yield of BHET. Therefore, $[\mathrm{Bmim}] \mathrm{ZnCl}_{3}$ has excellent reusable performance in glycolysis of PET under the given conditions.

3.3.4. Effect of Raw Material on the Glycolysis of PET. In order to investigate the effects of different raw materials, a comparison of the glycolysis reaction of different PET products in local market was carried out and the results were shown in Table 2. It indicates that the depolymerization of waste bottle, which is all of PET products, could be effectively catalyzed by $[\mathrm{Bmim}] \mathrm{ZnCl}_{3}$. It is also clear from Table 3 that yield of BHET was $66.8 \%$ with waste bottle of edible oil, which might be because thickness of edible oil bottle was deeper than that of other products of PET in this paper. 


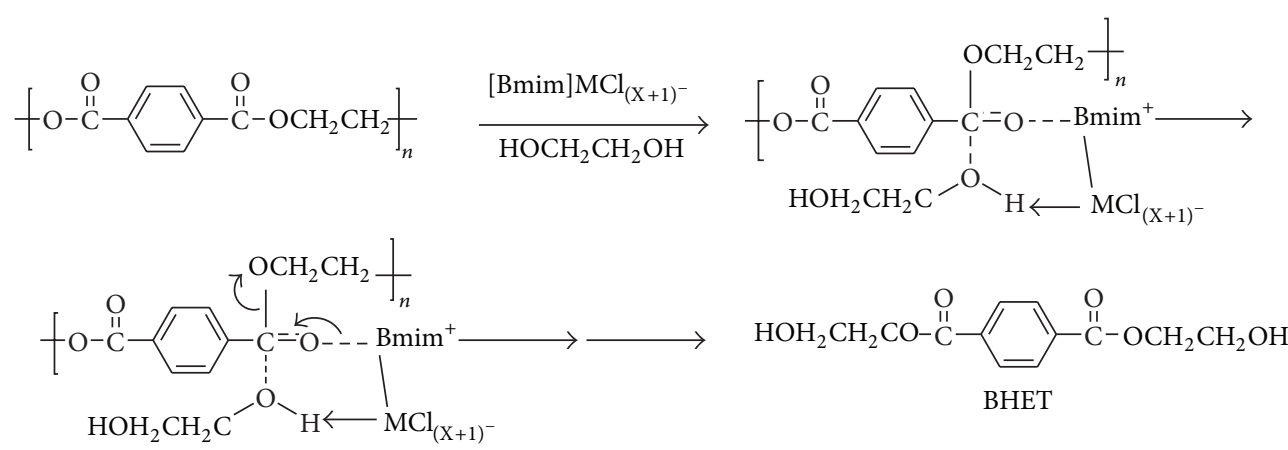

SCHEME 2: Mechanism of the glycolysis of PET in the presence of metal-containing ionic liquids.

TABLE 3: The effects of size on the glycolysis of PET ${ }^{\mathrm{a}}$.

\begin{tabular}{lcc}
\hline Size of PET $\left(\mathrm{mm}^{2}\right)$ & Conversion $(\%)$ & Yield (\%) \\
\hline 0.5 & 100 & 81.4 \\
1 & 97.9 & 83.3 \\
2 & 95.5 & 74.6 \\
3 & 93.7 & 69.3 \\
4 & 88.8 & 64.8 \\
\hline
\end{tabular}

${ }^{a}$ Reaction conditions: PET $2 \mathrm{~g}$; $[\mathrm{Bmim}] \mathrm{ZnCl}_{3} 1 \mathrm{wt} \%$; reaction time $5 \mathrm{~h}$; reaction temperature $180^{\circ} \mathrm{C}$.

3.3.5. Effect of PET Size on the Glycolysis. Table 3 showed the effect of PET size on reaction results. According to Table 3, the size of PET was a significant influence on reaction results. With decreasing of the size, both the PET conversion and BHET yield were increased greatly. Under the given conditions, when the PET size was $4 \mathrm{~mm}^{2}$, PET conversion and BHET yield were $88.8 \%$ and $64.8 \%$. However, when decreasing the size from $4 \mathrm{~mm}^{2}$ to $1 \mathrm{~mm}^{2}$, the glycolysis of PET arrived at $97.9 \%$ and BHET yield reached $83.3 \%$. It was because PET was a macromolecule material and dissolving of PET in EG was very slow, and decreasing the size of PET was beneficial for increasing available surface area for the reaction [27]. Furthermore, the solubility of PET was the rate determining step in the glycolysis reaction. Therefore, the dissolving and glycolysis of PET in EG were accelerated when its size was decreased.

3.3.6. Reaction Mechanism of the Glycolysis. Based on the results of this study, a reasonable catalytic cycle was proposed for the glycolysis over the metal-containing ionic liquids catalyst (Scheme 2). The cation in the catalyst interacts with the carbonyl oxygen $(\mathrm{C}=\mathrm{O})$ in the ester, and then the oxygen in the hydroxyl of ethylene glycol attacks the carbon cation of the ester group, forming a tetrahedral intermediate. Afterwards, the hydrogen leaves the ethylene glycol. Then, the electrons on the oxygen in $-\mathrm{OM}$ transfer form $\mathrm{C}=\mathrm{O}$. The acyl-oxygen cleaves, and the $-\mathrm{OCH}_{2} \mathrm{CH}_{2}$ - group leaves, combining with $\mathrm{H}^{+}$to form $\mathrm{HOCH}_{2} \mathrm{CH}_{2}-$. These transfer processes repeat, and BHET monomer is formed.

\section{Conclusions}

Metal-containing ionic liquids as $[\mathrm{Bmim}] \mathrm{ZnCl}_{3}$, $[\mathrm{Bmim}] \mathrm{MnCl}_{3},[\mathrm{Bmim}] \mathrm{PbCl}_{3},[\mathrm{Bmim}] \mathrm{FeCl}_{4},[\mathrm{Bmim}] \mathrm{NiCl}_{3}$, $[\mathrm{Bmim}] \mathrm{SnCl}_{3}, \quad[\mathrm{Bmim}] \mathrm{AlCl}_{4}$, and $[\mathrm{Bmim}] \mathrm{CuCl}_{3}$ were prepared and the different catalytic activity in the glycolysis of PET was shown. In the presence of $[\mathrm{Bmim}] \mathrm{ZnCl}_{3}$, the conversion of PET was achieved $97.9 \%$ and the BHET was yielded to $83.3 \%$ under the optimized reaction conditions. And at the same time, the influences of the source and the size of PET waste were investigated. Moreover, $[\mathrm{Bmim}] \mathrm{ZnCl}_{3}$ could be reused six times without obvious decrease in yield of BHET.

\section{Conflict of Interests}

The authors declare that there is no conflict of interests regarding the publication of this paper.

\section{Acknowledgments}

This work was supported by the Talented Young Innovation Project of Harbin Science and Technology Bureau (no. 2011RFQXG029).

\section{References}

[1] V. Sinha, M. R. Patel, and J. V. Patel, "Pet waste management by chemical recycling: a review," Journal of Polymers and the Environment, vol. 18, no. 1, pp. 8-25, 2010.

[2] D. Paszun and T. Spychaj, "Chemical recycling of poly(ethylene terephthalate)," Industrial and Engineering Chemistry Research, vol. 36, no. 4, pp. 1373-1383, 1997.

[3] S. Mitsuhiro, M. Taiji, Y. Ryutoku, and L. H. Meng, "Depolymerization of poly(butylene terephthalate) using high-temperature and high-pressure methanol," Journal of Applied Polymer Science, vol. 77, no. 14, pp. 3228-3233, 2000.

[4] K. Zenda and T. Funazukuri, "Depolymerization of poly(ethylene terephthalate) in dilute aqueous ammonia solution under hydrothermal conditions," Journal of Chemical Technology and Biotechnology, vol. 83, no. 10, pp. 1381-1386, 2008. 
[5] G. P. Karayannidis, A. K. Nikolaidis, I. D. Sideridou, D. N. Bikiaris, and D. S. Achilias, "Chemical recycling of PET by glycolysis: polymerization and characterization of the dimethacrylated glycolysate," Macromolecular Materials and Engineering, vol. 291, no. 11, pp. 1338-1347, 2006.

[6] H. Kurokawa, M.-A. Ohshima, K. Sugiyama, and H. Miura, "Methanolysis of polyethylene terephthalate (PET) in the presence of aluminium tiisopropoxide catalyst to form dimethyl terephthalate and ethylene glycol," Polymer Degradation and Stability, vol. 79, no. 3, pp. 529-533, 2003.

[7] S. R. Shukla and A. M. Harad, "Aminolysis of polyethylene terephthalate waste," Polymer Degradation and Stability, vol. 91, no. 8, pp. 1850-1854, 2006.

[8] F. F. Chen, G. H. Wang, C. Shi et al., "Kinetics of glycolysis of poly(ethylene terephthalate) under microwave irradiation," Journal of Applied Polymer Science, vol. 127, no. 4, pp. 2809-2815, 2013.

[9] Y. S. Parab, N. D. Pingale, and S. R. Shukla, "Aminolytic depolymerization of poly (ethylene terephthalate) bottle waste by conventional and microwave irradiation heating," Journal of Applied Polymer Science, vol. 125, no. 2, pp. 1103-1107, 2012.

[10] R. V. Shah, V. S. Borude, and S. R. Shukla, "Recycling of PET waste using 3-amino-1-propanol by conventional or microwave irradiation and synthesis of bis-oxazin there from," Journal of Applied Polymer Science, vol. 127, no. 1, pp. 323-328, 2013.

[11] R. V. Shah and S. R. Shukla, "Effective aminolytic depolymerization of poly(ethylene terephthalate) waste and synthesis of bisoxazoline therefrom," Journal of Applied Polymer Science, vol. 125, no. 5, pp. 3666-3675, 2012.

[12] M. Ghaemy and K. Mossaddegh, "Depolymerisation of poly(ethylene terephthalate) fibre wastes using ethylene glycol," Polymer Degradation and Stability, vol. 90, no. 3, pp. 570-576, 2005.

[13] S. Baliga and W. T. Wong, "Depolymerization of poly(ethylene terephthalate) recycled from post-consumer soft-drink bottles," Journal of Polymer Science A: Polymer Chemistry, vol. 27, no. 6, pp. 2071-2082, 1989.

[14] K. Troev, G. Grancharov, R. Tsevi, and I. Gitsov, "A novel catalyst for the glycolysis of poly(ethylene terephthalate)," Journal of Applied Polymer Science, vol. 90, no. 4, pp. 1148-1152, 2003.

[15] H. Wang, R. Y. Yan, Z. X. Li, X. P. Zhang, and S. J. Zhang, "Fe-containing magnetic ionic liquid as an effective catalyst for the glycolysis of poly(ethylene terephthalate)," Catalysis Communications, vol. 11, no. 8, pp. 763-767, 2010.

[16] T. Yoshioka, T. Handa, G. Grause, Z. G. Lei, H. Inomata, and T. E. Mizoguchi, "Effects of metal oxides on the pyrolysis of poly(ethylene terephthalate)," Journal of Analytical and Applied Pyrolysis, vol. 73, no. 1, pp. 139-144, 2005.

[17] V. I. Pârvulescu and C. R. Hardacre, "Catalysis in ionic liquids," Chemical Reviews, vol. 107, no. 6, pp. 2615-2665, 2007.

[18] F. Liu, X. Cui, S. Yu, Z. Li, and X. Ge, "Hydrolysis reaction of poly(ethylene terephthalate) using ionic liquids as solvent and catalyst," Journal of Applied Polymer Science, vol. 114, no. 6, pp. 3561-3565, 2009.

[19] H. Wang, Z. X. Li, Y. Q. Liu, X. Zhang, and S. J. Zhang, "Degradation of poly(ethylene terephthalate) using ionic liquids," Green Chemistry, vol. 11, no. 10, pp. 1568-1575, 2009.

[20] H. Wang, Y. Q. Liu, Z. X. Li, X. P. Zhang, S. J. Zhang, and Y. Q. Zhang, "Glycolysis of poly(ethylene terephthalate) catalyzed by ionic liquids," European Polymer Journal, vol. 45, no. 5, pp. 1535-1544, 2009.
[21] Q. F. Yue, C. X. Wang, L. N. Zhang, Y. Ni, and Y. X. Jin, "Glycolysis of poly(ethylene terephthalate) (PET) using basic ionic liquids as catalysts," Polymer Degradation and Stability, vol. 96, no. 4, pp. 399-403, 2011.

[22] C. H. Chen, C. Y. Chen, Y. W. Lo, C. F. Mao, and W. T. Liao, "Studies of glycolysis of poly(ethylene terephthalate) recycled from postconsumer soft-drink bottles. I. Influences of glycolysis conditions," Journal of Applied Polymer Science, vol. 80, no. 7, pp. 943-948, 2001.

[23] M. Imran, B.-K. Kim, M. Han, B. G. Cho, and D. H. Kim, "Suband supercritical glycolysis of polyethylene terephthalate (PET) into the monomer bis(2-hydroxyethyl) terephthalate (BHET)," Polymer Degradation and Stability, vol. 95, no. 9, pp. 1686-1693, 2010.

[24] S. R. Shukla, V. Palekar, and N. Pingale, "Zeolite catalyzed glycolysis of polyethylene terephthalate bottle waste," Journal of Applied Polymer Science, vol. 110, no. 1, pp. 501-506, 2008.

[25] N. D. Pingale, V. S. Palekar, and S. R. Shukla, "Glycolysis of postconsumer polyethylene terephthalate waste," Journal of Applied Polymer Science, vol. 115, no. 1, pp. 249-254, 2010.

[26] Z. Y. Duan, Y. L. Gu, and Y. Q. Deng, "Green and moisture-stable Lewis acidic ionic liquids (choline chloride $\cdot \mathrm{xZnCl}_{2}$ ) catalyzed protection of carbonyls at room temperature under solvent-free conditions," Catalysis Communications, vol. 7, no. 9, pp. 651-656, 2006.

[27] G. P. Karayannidis and D. S. Achilias, "Chemical recycling of poly(ethylene terephthalate)," Macromolecular Materials and Engineering, vol. 292, no. 2, pp. 128-146, 2007. 

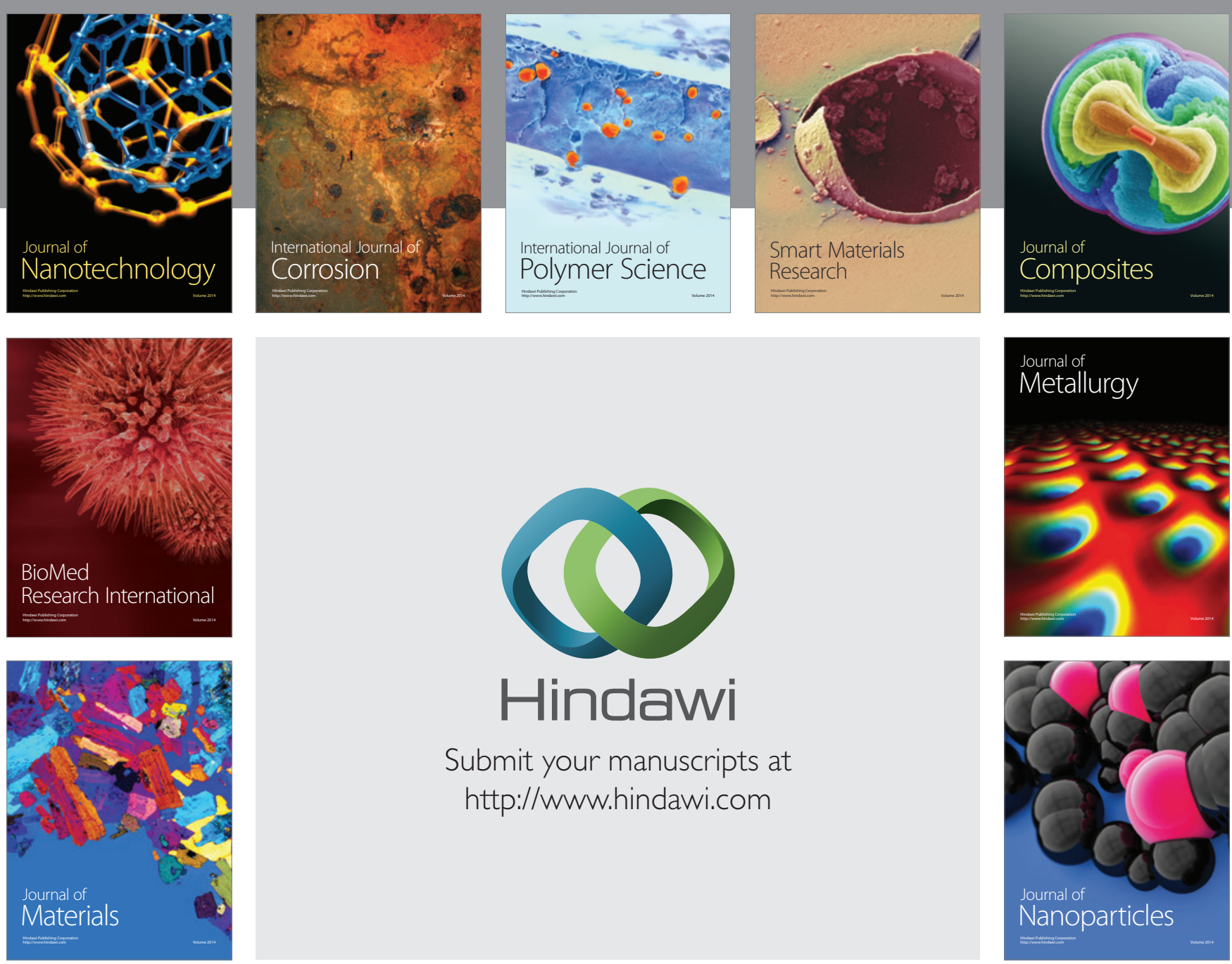

Submit your manuscripts at http://www.hindawi.com
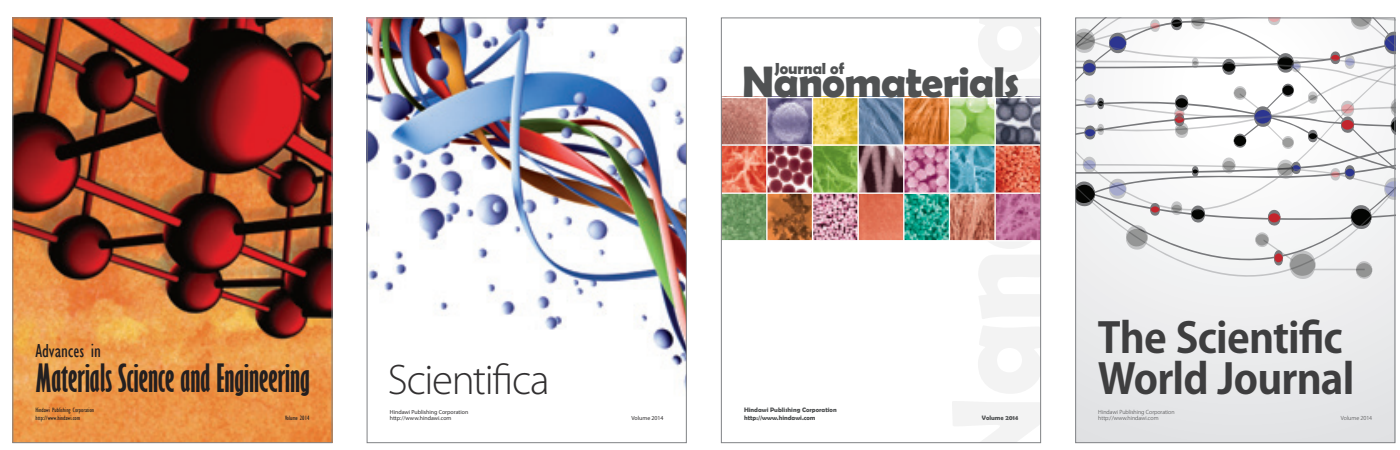

\section{The Scientific World Journal}
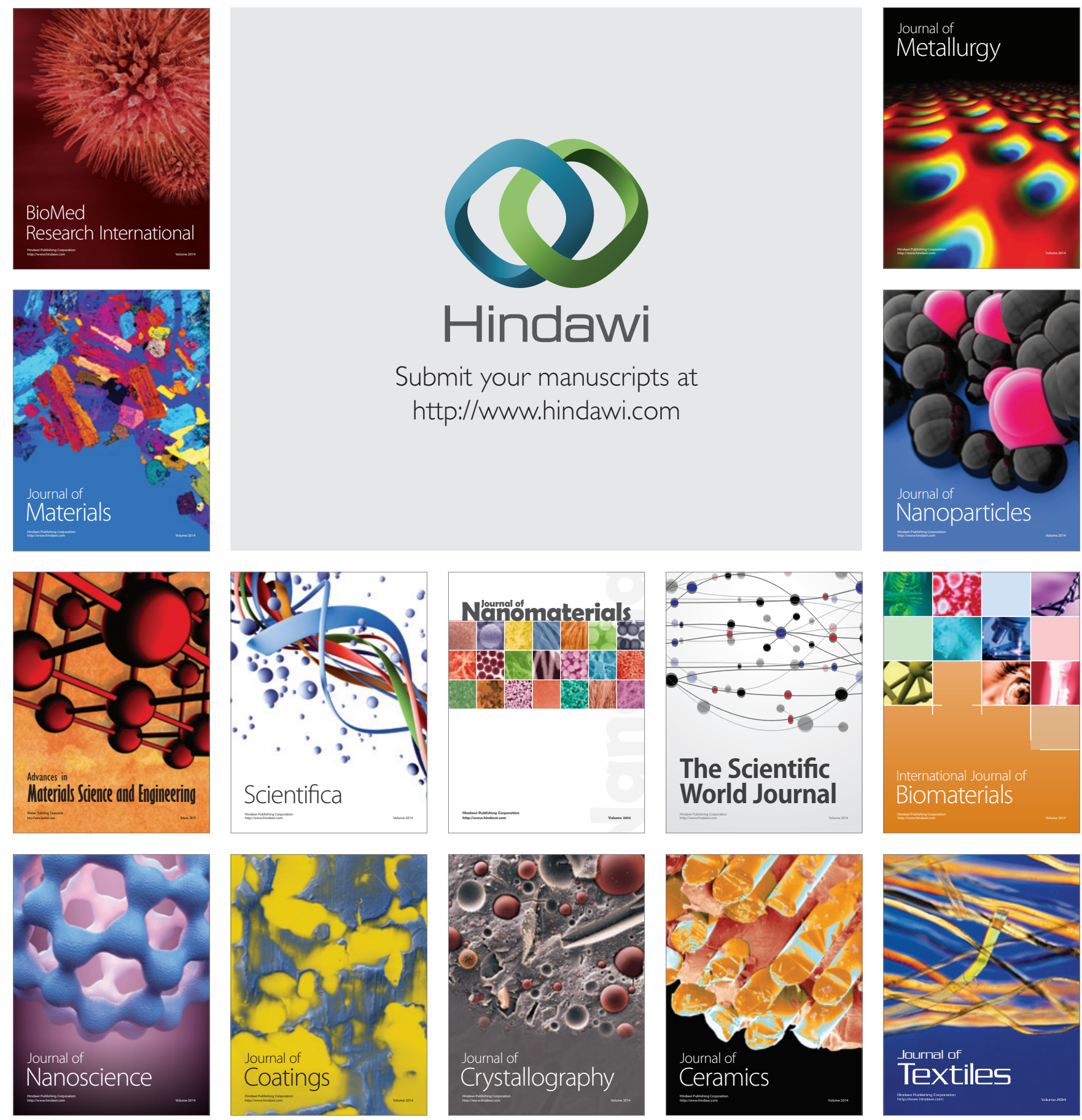